\title{
ANÁLISIS DEL LENGUAJE DE LA PEDAGOGÍA. CARACTERIZACIÓN Y TIPOLOGÍA
}

\author{
REBECA SOLER COSTA \\ Universidad de Zaragoza
}

\begin{abstract}
RESUMEN: Conocer el lenguaje de una disciplina científica permite entender mejor su epistemología. El lenguaje pedagógico precisa de un análisis, dado que no ha sido objeto de estudio. Por ello, el objetivo de este artículo es mostrar su caracterización lingüística del lenguaje de la Pedagogía. Se realiza una revisión bibliográfica del concepto de «lenguas especiales» y se analiza el léxico y los factores extralingüísticos. Se utiliza una metodología de investigación cualitativa, en una dimensión descriptiva. Los resultados muestran que es un «lenguaje sectorial». La caracterización del léxico y de los factores pragmáticos muestra que este lenguaje se sitúa en un «nivel umbral». Esta caracterización permite conocer cómo la Pedagogía construye su lenguaje, cómo sus hablantes transmiten los significados.
\end{abstract}

PALABRAS CLAVE: lenguaje de la Pedagogía; interacción didáctica; léxico; factores pragmáticos; nivel umbral.

\section{Analysis of the language of Pedagogy. Characterization and typology}

ABSTRACT: Knowing the language of a scientific discipline allows a better understanding of its epistemology. The pedagogical language needs analysis, since it has not been studied. Therefore, the aim of this article is to show the linguistic characterization of the language of Pedagogy. A literature review of the concept of "special languages» is developed and an analysis of the lexis and the extra linguistic factors is carried out. It is used a qualitative research methodology, in a descriptive dimension. The results show that it is a "sector language». The characterization of the lexis and pragmatic factors shows that this language belongs to a «threshold level». This characterization allows to know how Pedagogy builds its language, how its speakers convey the meanings.

KEY WORDS: language of Pedagogy; didactic interaction; lexis; pragmatic factors; threshold level.

\section{INTRODUCCIÓN}

El lenguaje de la Pedagogía no ha recibido una atención especial en su estudio a diferencia de otro tipo de lenguajes de especialidad. Si bien los lenguajes del ámbito médico, administrativo o judicial se consideran «lenguajes científico-técnicos» y cuentan con numerosas publicaciones a modo de diccionarios de especialidad para facilitar la comprensión de sus términos, el lenguaje de la Educación no ha suscitado nunca ese interés. En cambio es necesario conocer cómo los docentes se comunican con otros profesionales y con sus alumnos en el desarrollo de los procesos didácticos, si bien el lenguaje es el vehículo de comunicación que utilizan para resolver los problemas, explicar los contenidos, interactuar con los alumnos, fomentar su participación en el aula, trasladar la evolución académica de un alumno a sus padres, etc.

El lenguaje de los docentes es intercomprensible por su comunidad de hablantes (profesores, padres, madres, alumnos, orientadores, asesores, etc.) porque permite la 
comunicación, posibilita que sus agentes expresen sus necesidades denominativas. Ello hace que se considere un "lenguaje sectorial», es decir, un lenguaje que en la tipología que plantea B. Rodríguez (1981) sobre las «lenguas especiales» se sitúa en una zona intermedia de la escalar polar entre los «argots» (lenguas esotéricas con finalidad críptica: caló) y los «lenguajes científico-técnicos» (nomenclaturas específicas de disciplinas científicas: lenguaje de los abogados, por ejemplo).

Los «lenguajes sectoriales» son lenguajes de jergas profesionales que identifican un dominio social, un ámbito de actividad específico. El sistema lingüístico que utilizan es el de la lengua general pero son los usos pragmáticos y extralingüísticos los que le confieren una especificidad propia.

El lenguaje de la Educación es un «lenguaje sectorial» con unas características comunicativas, pragmáticas y con unos códigos lingüísticos que sólo conoce la comunidad epistemológica de la Pedagogía. Dado que la lengua surge fruto del diálogo verbal y de la interlocución a través de estrategias cognitivo-comunicativas de sus hablantes, los agentes que intervienen en los procesos educativos y las situaciones en las que éstas tiene lugar lo sitúan en esa zona intermedia, en lo que se denomina un «nivel umbral».

De forma que es el léxico el elemento que permite caracterizar este lenguaje, el elemento que ofrece el marco epistemológico en la delimitación de los objetos y relaciones que los miembros de la comunidad educativa comparten, aunque a ello hay que sumar los factores extralingüísticos que intervienen en las situaciones comunicativas (los criterios pragmáticos). En este sentido, se realiza un análisis del concepto de «lenguas especiales» para poder caracterizar el lenguaje de la Educación y comprender qué elementos hacen posible que los profesionales que se dedican a la enseñanza se comuniquen eficazmente con hablantes especialistas y con no especialistas. Además ello permitirá conocer los mecanismos lingüísticos que gobiernan sus enunciados, la construcción de sus discursos y los significados.

\section{REVISIÓN TEÓRICA DEL CONCEPTO «LENGUAS ESPECIALES»: ESTADO DE LA CUESTIÓN}

Desde una perspectiva diacrónica las denominadas «lenguas especiales» han recibido diversas denominaciones. Lingüistas como Vendryes (1929) entienden que son «lenguas especiales» aquéllas que se utilizan en circunstancias especiales por grupos específicos de hablantes. De hecho, Vendryes (1929) fue uno de los primeros lingüistas, clásico y moderno al mismo tiempo, que proporcionó una definición de «lengua especial»: «une langue qui n'est employée que par des groupes d'individus placés dans des circonstances spéciales» (Vendryes, 1929: 276). Esta afirmación supone considerar que una de las características de las «lenguas especiales» es el número limitado de sus usuarios, así como de las circunstancias específicas en que se utilizan.

Nótese que esta definición establece el estatus de las «lenguas especiales» en función de información lingüísticamente externa: los hablantes y las situaciones comunicativas. Sin embargo, en líneas posteriores, añade una característica más de las «lenguas especiales»: considera que la propiedad interna de «especial» (Vendryes, 1929: 277) se debe a que están en relación con otra lengua de la que son 
subsidiarias. Ello implica considerar que todas las «lenguas especiales» adoptan los mismos patrones:

[...] adaptar el lenguaje a las funciones del grupo que lo usa [...] si bien las lenguas especiales pueden ser diferentes de la ordinaria (un caso típico sería el latín, como lengua religiosa o culta), lo más frecuente es que se desarrollen sobre el fondo común de una lengua viva1 (Martín, 1997: 318).

Casares (1969) utiliza la denominación «hablas particulares» O «particularismos», situándolos dentro de la lengua común, pero fuera de ella. Distingue tres tipos posibles, tres clases de "particularismos» o "hablas que sólo tienen el carácter común de ser respectivamente peculiares de una determinada profesión» (Casares, 1950: 281). En primer lugar, enuncia el «particularismo social», formado por el argot o germanía y caracterizado por poseer un léxico propio que refleja una tendencia al cripticismo para evitar que el habla sea comprendida por personas ajenas al grupo social. Así, el léxico de estos «particularismos sociales» es «[...] un producto artificial y parasitario creado voluntariamente por un núcleo de hablantes como defensa contra sus fuerzas sociales que le son antagónicas»(Casares, 1950: 273).

Los términos que utilizan los hablantes de estos "particularismos sociales» tienen propiedades connotativas que los convierten en crípticos e inteligibles únicamente por la minoría que los habla. La estructura sintáctica y morfológica es semejante a la de la lengua común y muestra una tendencia críptica, utilizada en una «[...] zona restringida de la lengua familiar, que limita al sur con la germanía y el caló, al este y oeste con la terminología artesana y al norte con el tecnicismo científico» (Ibid.: 281).

En segundo lugar, Casares (1950) expone el "particularismo profesional», formado por hablas que se caracterizan por pertenecer a una profesión. En este tipo de «habla particular» incluye la jerga, el particularismo artesanal y el particularismo técnico. Este "particularismo técnico» se caracteriza por poseer un léxico inestable con muchos préstamos (Ibid.: 288).

Por último, señala los «particularismos geográficos», los cuales «[...] no forman parte del patrimonio lingüístico general porque no salvan las fronteras geográficas del ámbito en que viven y circulan»(Casares, 1950: 294). Poseen vocabulario tradicional, «[...] al que se han añadido posteriormente algunos neologismos relacionados con las nuevas escuelas artísticas o con procedimientos antes desconocidos» (Ibid.: 281).

Por otro lado, Engel (1970) muestra que el término lengua de especialidad tiene varios significados. En un sentido restringido (S1), lengua de especialidad alude al léxico específico de los dominios concretos de una ciencia en particular. Esta acepción incluye los elementos de la lengua común (C) —vocabulario, fraseología,

\footnotetext{
1 Al hablar de lenguas, se puede hacer alusión a tres tipos: la lengua materna —aquélla que adquirimos de nuestras madres, por ello, tiene dicha denominación-, las lenguas muertas -aquéllas que no tienen hablantes nativos y, aunque tengan textos escritos, constituyen una modalidad inalterable; por ejemplo, el griego o el latín-y, por último, las lenguas vivas -aquéllas que llevan en sí mismas una cultura histórica y tienen hablantes que las utilizan; se trata de una realidad que experimentamos, que utilizamos, que es perceptible. La oralidad constituye la característica más afín de las lenguas vivas-.
} 
sintaxis, morfología, semántica- que aparecen en los Manuales de Química, Física, Biología, etc. y que son utilizados exclusivamente por los especialistas, pero sin que aparezcan en la lengua común (C). En un sentido más amplio (S2), el concepto de lenguas especializadas remite a la lengua de las ciencias particulares, en general, con la inclusión de los términos que aparecen en la lengua común (C).

De estas propiedades de los lenguajes de especialidad, Engel (1970: 33-35) deriva la siguiente formulación sobre la lengua científica: L = S2 - S1 - C. En consecuencia, ésta es la que forma parte de todos los dominios de las ciencias, pero que no lo hace de la lengua común.

Beccaria (1973) muestra una clasificación mucho más amplia de las «lenguas especiales». Diferencia 18 tipos de lenguas de especialidad en un trabajo sobre las «lenguas sectoriales en Italia».Trujillo (1974) considera que existe una distinción teórica esencial entre el «lenguaje especial» y el lenguaje común, debido a los diferentes usos técnicos y no técnicos de los significantes léxicos.

Berruto y Berretta (1977) escogen la denominación de «lenguas especiales»y estudian las relaciones que se producen entre éstas y la lengua común. Sostienen que la especialización de un término que pasa a formar parte del léxico específico de una «lengua especial» o la vulgarización de otro a través de su «destecnificación» (Ibid.: 13) y consiguiente inclusión en el léxico de la lengua común, contribuyen en la evolución de la lengua. Les interesa la aportación de estas relaciones en el desarrollo de la lengua, en el proceso constante de creación y muerte de palabras y significados.

Hoffmann (1979) hace uso de la denominación lenguajes de especialidad y estima que, para ser considerados como tales y diferenciados de la lengua común, deben contener elementos extralingüísticos y comunicativos que sean específicos. Para ello, tiene en cuenta los usos de esos lenguajes, la temática utilizada y las intenciones o condiciones que subyacen al acto comunicativo:

A complete set of linguistic phenomena occurring within a definite sphere of communication and limited by specific subjects, intentions and conditions (Hoffmann, 1979: 86).

Desde una perspectiva fundamentalmente sociológica, Hernán (1979) utiliza la denominación «lenguas especiales» o lenguas de minorías. Considera que las llamadas «lenguas especiales» son «[...] comportamientos lingüísticos divergentes o especiales de ciertas clases o grupos, productos de la segmentación social» (Ibid.: 68). Esta consideración difiere de la anterior al excluir las variedades diatópicas y psicológicas y centrarse únicamente en un criterio diastrático, aunque ello no significa que no admita el que estas lenguas nazcan de una lengua común de la cual se alimentan. De hecho, al constituir bloques lingüísticos diferentes al de la lengua común, se produce una especialización de términos a los que remite una determinada actividad profesional o particular de un grupo social. Se trata, pues, de grupos sociales o profesionales -obsérvese de nuevo, el peso del componente sociológico-.

En esta consideración cabría plantearse si existe un componente temático que distinga taxativamente los tres tipos de «lenguas especiales». Si son utilizadas por grupos sociales o profesionales, indirectamente se está haciendo uso de un componente temático a fortiori que, como ya se ha planteado anteriormente, 
contribuye a establecer diferencias en la tipología de las «lenguas especiales». Nótese que este autor atribuye al vocabulario de estas lenguas procesos de especialización léxica en los que un elemento léxico puede actuar, bien como término independiente con su significado originario, bien con un sentido especializado. Esto supone aceptar que habrá términos cuyo significado especializado sea desconocido para hablantes que no formen parte de un determinado grupo social.

Las coordenadas indicadas de carácter secreto o argótico y de grupo social específico inexorablemente muestran la variedad constitutiva de las «lenguas especiales» que se ha denominado argot. Ejemplos de esta especialización léxica en tareas del hogar desarrolladas por mujeres son, según este autor: pespunte, sisa, rangla (Ibid.) y en el mundo del automóvil carburador (Ibid.: 69). En esta misma dirección se sitúan los trabajos de Berruto y Berretta (1977).

Tanto Hernán (1977), como Berruto y Berretta (1977), consideran que la delimitación entre lengua común y «lengua especial» es difusa, porque existen trasvases continuos de elementos léxicos de la lengua común hacia las «lenguas especiales» y viceversa. Lógicamente, esto supone admitir que, si un término de la lengua común acaba en el léxico de una "lengua especial», es porque se ha producido una especialización léxica. Si sucede en sentido contrario, esto es, un término de la «lengua especial» se «banaliza» y pierde su significado específico, se une al léxico de la lengua general.

Rodado constituye un ejemplo de este proceso; adquiere el sentido de experimentado, conocedor de y se aplica a personas en la lengua común: Luis está muy rodado en cuestiones de economía internacional. Este significado viene del latín rotare, cuyo significado hacía referencia al hecho de que un cuerpo diera vueltas alrededor de su eje, moviéndose hacia otro lugar o permaneciendo en el mismo. Con este nuevo sentido, se trasvasa a la lengua común. De forma que pasa a ser utilizado en contextos cotidianos, como, por ejemplo: Juan está muy rodado.

En cambio, para Hernán (1979) las «lenguas especiales» son de dos tipos: «lenguas abiertas» - formadas por las «lenguas especiales» y las lenguas de la artesanía o de los oficios_- y las «lenguas cerradas» — compuestas por jergas, argots y lenguas de la juventud-. La diferencia entre los dos tipos de lenguas propuestas por Hernán (1979) reside en el carácter críptico de las últimas. En la tipología a la que me adscribo — la propuesta por Rodríguez (1981)—, estas lenguas secretas serían los argots y, por tanto, se trataría de una categoría de «lenguas especiales». Se incluirían las jergas, junto con los argots.

Sin embargo, esta caracterización difiere de la nuestra en cuanto al primer tipo de «lenguas especiales» presentado. Las denominadas, según Hernán (1979), «lenguas abiertas» son lenguas profesionales ${ }^{2}$ que surgen de una necesidad comunicativa. Esto es, se acompañan de un propósito, tienen lugar en una situación comunicativa y se utilizan en un grupo determinado de interlocutores, especialistas en el ámbito en el que se emplea dicha lengua profesional. En consecuencia, estas «lenguas

2 Según Hernán (1979) las «lenguas profesionales» son «especializaciones de la lengua estándar que corresponden a diferentes ramas de la actividad humana [...] Las lenguas profesionales surgen, en todas partes y en todo tiempo con algunas variantes de extensión y riqueza, por la necesidad que tienen las diversas profesiones de precisar y fijar sus propias actividades, instrumentos, técnicas y conceptos particulares» (Ibid.: 69). 
abiertas» son «lenguajes científico-técnicos» como, por ejemplo, el lenguaje de la Medicina, del Derecho, de la Ingeniería Informática, etc.

No obstante, esta denominación se ciñe a la propuesta de Cabré (2003) sobre las lenguas de especialidad. Esta lingüista defiende que, para hablar de lenguas de especialidad, es preciso considerar, no sólo sus unidades lingüísticas, sino también todos los elementos partícipes del proceso de comunicación en el que tiene lugar la interacción. Esto es, estos lenguajes se delimitan por su temática y por sus ámbitos de uso. Por ello, la idea que se está defendiendo es que constituyen un enfoque lingüístico, a partir de un criterio eminentemente pragmático.

En sintonía con este planteamiento, Lerat (1997) estima que son lenguas especializadas por el carácter temático y por los usos que siempre se circunscriben a ámbitos profesionales. En esta misma dirección se sitúa el trabajo de Lerat (1997), quien admite que sólo se puede hablar de lenguas especializadas si su temática es especializada y los usos de la lengua tienen lugar en ámbitos profesionales.

Así pues, serviría, de igual modo, la denominación de lenguas profesionales defendida por Hernán (1979), quien propone que las lenguas profesionales pertenecen a lo que él denomina «lenguas abiertas». Las incluye en esta categoría porque afirma que no son lenguas que pretendan guardar las distancias con otras personas no afines al ámbito profesional, sino, más bien, porque se trata de lenguas en las que todos los hablantes pueden tomar parte - aunque, queda claro, habrá cierto léxico utilizado mayoritariamente por un sector más próximo a la temática de la conversación, más identificado con algunos términos-.

Esto significa que, si bien una parte del vocabulario utilizado en la conversación tiene más uso con determinados grupos de hablantes, pertenecientes al mismo sector profesional —es decir, existe un léxico especializado-, habrá, por otro lado, cierto léxico que pase a la lengua común —léxico «banalizado»—y se adopte y utilice en la misma con total normalidad. Si la lengua profesional no llega a dominarse y a utilizarse por todos los hablantes, las razones son obvias: no interesa a toda la comunidad, únicamente al sector profesional respectivo. Sería, una especie de extensión del lenguaje normal, condicionada por necesidades particulares.

Hernán (1979) incluye dentro de esta variación denominativa de las tradicionales «lenguas especiales», el «lenguaje científico-técnico». Argumenta que este lenguaje posee elementos lingüísticos greco-latinos, fácilmente reconocibles por el mundo occidental, incluso utiliza grafemas semejantes. Por esta razón, adivinar el significado de un término científico no tiene mayor dificultad, ya que el valor semántico de éstos es semejante en casi todas las lenguas modernas. En igualdad de condiciones, las siglas y las abreviaturas suelen ser universales y su publicación en glosarios agiliza su comprensión. Según este mismo autor, una característica negativa de este lenguaje es su gran inestabilidad léxica, debido a la constante evolución a la que está sometido.

Sager, Dungworth y McDonald (1980) afirman que son lenguajes de especialidad que tienen una marcada perspectiva pragmática con un componente conceptual y lingüístico. Consideran que son lenguajes con propósitos específicos (language for special purposes) y que su uso debe ser exclusivo de ese ámbito didáctico. Por ello, consideran que es más apropiado utilizar la expresión «lenguajes especiales» (special languages) o, incluso de forma todavía más precisa lenguajes especializados por la temática o lenguajes de especialidad determinados por la temática (special subject languages). 
Posteriormente, el profesor Alarcos (1982) soslaya la denominación de «lenguajes especiales» e incluye, dentro de éstos, los tres tipos ya enunciados por Rodríguez (1981): los argots o jergas, definidos como lenguas de grupos sociales con finalidad críptica —argot de los malhechores, argot sexual de la prostitución, argot carcelario, argot de los delincuentes-; los «lenguajes sectoriales», aquéllos relacionados con actividades y profesiones concretas pero que no persiguen finalidad críptica alguna —el lenguaje del deporte, de la política—; y los «lenguajes científico-técnicos», en los que no existe finalidad críptica pero resultan incomprensibles para personas que no forman parte de la actividad profesional en la que se utilizan —lenguaje de la Biología, de la Medicina, del Arte, de la Informática, de la Economía, lenguaje Jurídico, etc.-.

Kocourek (1982) y Rondeau (1983) admiten varias denominaciones para estas «lenguas especiales». Consideran sinónimos los términos lenguajes de especialidad, lenguajes especializados y lenguajes con propósitos específicos. Es interesante la aproximación que ofrece Kocourek (1982) sobre los lenguajes de especialidad, porque incluye dos consideraciones importantes. La primera perspectiva remite a la consideración de éstos como sistemas de comunicación. Así, postula la transmisión y el intercambio de información, utilizando varios códigos simultáneamente.

Esta concepción está relacionada con la semiótica de Lerat (1997): el lenguaje en su grado máximo de perfección y eficacia es, lógicamente, el lenguaje humano, pero también existen otros sistemas tridimensionales de comunicación, como las maquetas, el relieve, los mapas, los dibujos, los signos ideográficos, las fotografías, los esquemas, las ilustraciones, las nomenclaturas, los números, las fórmulas, etc. La segunda perspectiva de análisis considera que estos lenguajes forman parte de las lenguas naturales - terreno que genera opiniones contrarias sobre la diferencia entre estos lenguajes y la lengua general-. En definitiva:

[...] la langue de spécialité sera une sous-langue de la langue dite naturelle, enrichie d'éléments brachygraphiques, à savoir, abréviatifs et idéographiques, qui s'intègrent à elle en se conformant à ses servitudes grammaticales (Kocourek, 1982: 26).

En sentido análogo, Rondeau (1983) defiende que los lenguajes de especialidad son «simples variaciones léxicas del lenguaje general» (Cabré, 1993: 133), ya que «il faut noter que les expressions 'langue de spécialité' (langage spécialisé) et 'langue commune' ne recouvrent qu'un sous-ensemble de la langue, celui des lexèmes» (Ibid.). Ejemplos representativos de esta concepción serán el lenguaje deportivo, el jurídico, el burocrático-administrativo y, en general, todo lenguaje que no sea una variante del estándar. Los lingüistas procedentes de la lingüística teórica o descriptiva defienden esta posición:

Au sens propre il n'existe pas de langue du droit en soi mais seulement à l'intérieur de la langue française, un vocabulaire du droit et sans doute quelques tours syntaxiques spécifiques (Rey, 1976: 13).

La linguistique descriptive condamne les désignations de 'langue' technique et scientifique qui sont également impropres. Il convient plutôt de parler de vocabulaires, s'agissant d'emplois particuliers du français et de ses variétés qui font appel, pour la prononciation, la morphologie et la syntaxe, au fonds de la langue commune, caractère à partir duquel notre analyse établit des rapports fonctionnels mais non hiérarchisés (Quemada, 1978: 75). 
Varantola (1986) muestra una concepción diferente de los lenguajes especializados. Los define como subconjuntos pragmáticos dellenguaje que se utilizan por especialistas, en situaciones comunicativas específicas. Por ello, son intercomprensibles por los hablantes de una disciplina científica, y no lo son por los hablantes no especialistas: «special languages are semi-autonomous, complex semiotics systems based on and derived from general language; their use presupposes special education and is restricted to communication among specialists in the same or closely related fields».

Una concepción próxima a la propuesta por Varantola (1986) se encuentra en Beaugrande (1987), quien afirma que los lenguajes especializados son subconjuntos pragmáticos, que forman parte del lenguaje común. Esta posición también es compartida por otros autores, como, por ejemplo, Pitch y Draskau (1985) o Sager, Dungworth y McDonald (1980). No obstante, Beaugrande (1987) manifiesta la gran dificultad que presentan los lenguajes de especialidad a la hora de ser definidos:

One can of course select a domain and run through its linguistic resources in terms of some familiar scheme like phonology, morphology, lexicon, and the like. But surely the major aspect of LSP is its communicative potential, and the latter can be described only in a roundabout and incomplete fashion within such schemes (Beaugrande, 1987: 45).

Sin embargo, Becerra (1992) utiliza la denominación «lenguas especiales» y entiende que, bajo este epígrafe, se incluyen los «[...] subsistemas de la lengua estándar referidos principalmente al léxico o vocabulario, por medio de los cuales se identifica un determinado ámbito sociocultural» (Becerra, 1992: 9). Esta consideración, si bien admite que existen determinadas profesiones, oficios o diversiones, incluye la generación de variedades lingüísticas propias (Ibid.) que, por su importancia sociológica, se consideran «lenguas especiales».

Alonso-Cortés (1994) diferencia entre jergas y «lengua especial». Define jerga como habla peyorativa - la de los marineros-. Esto muestra una deficiente formación idiomática. Por otro lado, denomina «lengua especial» a aquélla utilizada por personas que poseen estudios y tienen una actitud educada. Por ejemplo, la lengua especial de la marina, haciendo mención al código empleado por personas educadas en la carrera universitaria (Ibid.).

Hay muchos otros lingüistas que se han dedicado al análisis de este concepto, imprescindible en el análisis del lenguaje de la Educación que se pretende realizar. Es preciso partir de este concepto lingüístico para poder analizar el lenguaje que utilizan los docentes, caracterizarlo y determinar su tipo lingüístico. Ello facilita la comunicación entre sus hablantes. De forma que cabe destacar en esta revisión histórica del concepto de «lenguas especiales» que la mayor parte de los autores consultados consideran que son «lenguas especiales» o lenguajes de especialidad aquéllos que se utilizan por un grupo específico de hablantes que comparten una temática y unas situaciones comunicativas con finalidad expresiva en las que suelen prevalecer criterios diastráticos - motivados por los usos que hacen los distintos grupos sociales de la lengua-y diafásicos — por las características de la situación ${ }^{3}$ -

3 En este sentido, se encuentran las teorías de BeCERra (1992), Berruto y Berreta (1977), Casares (1969), Duarte (1986), Engel (1970), González (2000), Gutiérrez (1998), Hoffmann (1979), Lerat (1997), Martín (1997), Martín, Ruiz, Santaella y Escánez (1996), Martínez 
Otros autores, como Kocourek (1982) y Rondeau (1983) prefieren las denominaciones de lenguajes de especialidad, lenguajes especializados y lenguajes con propósitos específicos. En sentido análogo, Calvi (2005) utiliza la denominación lenguajes con fines específicos. Charlton y Andras (2005) y Alcaraz (2006; 2007) hacen uso de la expresión «lenguas profesionales y académicas». Hernán (1979) prefieren hacer uso de las denominaciones «lenguas abiertas», «lenguas cerradas», lenguas de minorías, lenguas de la juventud y lenguas de oficios y de artesanía. (Hernán, 1979). Por último, Cordero (2009), en su publicación más reciente, emplea la denominación de lenguajes técnicos, «lenguajes especiales», «lenguas científicotécnicos», tecnolectos, "microlenguas» o "lenguaje diatécnico» atendiendo a las variedades lingüísticas y a los subcódigos que se generan.

\section{Objetivo y Metodología}

Las «lenguas especiales» han recibido diferentes denominaciones y, en algunos ámbitos científicos, han sido objeto de estudio empírico, con un análisis detallado de su léxico; consideramos necesaria esta misma indagación en el lenguaje de la Pedagogía. Así pues, el objetivo de esta investigación es mostrar la caracterización lingüística del lenguaje pedagógico, analizar su léxico y los factores extralingüísticos. No se asume un análisis semántico de los términos, ya que la naturaleza lingüística de este lenguaje muestra que es ontológico, de forma que las unidades léxicas ya tienen una asignación de un nombre o realidad referencial a un concepto.

Sin embargo, el hecho de centrar nuestra atención en el estudio del léxico de este lenguaje sí implica que éste tenga dominios léxicos y conceptuales, con valores lingüísticos especializados que conforman dominios semánticos, exclusivos de su comunidad de hablantes, esto es, de la comunidad epistemológica de la Pedagogía. Esta investigación se centra, pues, en el análisis de la terminología del lenguaje pedagógico a partir de un análisis exhaustivo de las principales corrientes lingüísticas. Se seguirá para ello una metodología de naturaleza cualitativodescriptiva (Taylor y Bogdan, 1992), concretada en el estudio del léxico (Rodríguez, 1981; Cabré, 1993; Lerat, 1997).

Para ello, se ha seleccionado, como muestra de la investigación, un conjunto de términos que han mantenido el significado en la lengua general y en el lenguaje de la Pedagogía; se han analizado términos que han sufrido diferentes grados de lexicalización, así como acrónimos y anglicismos, atendiendo a criterios de uso lingüístico en este lenguaje (diccionarios de Pedagogía, textos científicos y documentos sobre experiencias e innovaciones educativas). En general, los criterios de selección de los términos de la muestra han sido: la adecuación a las disciplinas de las Ciencias de la Educación, la actualidad y uso en el discurso pedagógico y la realidad referencial específica del ámbito al que remiten. Por estas razones, este corpus que se presenta cumple los requisitos de precisión lingüística y discursiva entre los miembros de la comunidad educativa.

(2006), Rodríguez (1981), Sager, Dungworth y McDonald (1980), Santamaría (2005), Schmitt (1992), Sevilla (2003), Trujillo (1974), Vendryes (1929), Wulf (1981). 


\section{RESULTADOS: CARACTERIZACIÓN LINGÜÍSTICA DE LAS «LENGUAS ESPECIALES»}

Los elementos que delimitan los usos específicos de las lenguas no están directamente relacionados con el sistema gramatical, sino que se refieren a la naturaleza de sus hablantes, a las situaciones comunicativas y al léxico que utilizan para designar sus realidades referenciales. Si bien los criterios más utilizados en la caracterización de las «lenguas especiales» responden a factores extralingüísticos, es importante conocer la existencia de un componente sociológico en tanto en cuanto «[...] la lengua es un hecho social y funciona dentro de los grupos sociales; cada grupo social crea y conforma su propia lengua» (Rodríguez y García, 1992: 2).

Además de este componente sociológico existe un criterio temático que contribuye a caracterizar a los lenguajes que presentan una variedad en su léxico respecto a la lengua general como es el lenguaje de la Educación: «[...] la lengua transmite unos contenidos, designa unos determinados objetos y relaciones» (Ibid.).

Los «argots» constituyen un signum social y tienen una función marcadamente expresiva que hace que sus hablantes se sientan identificados como grupo social. Por ello se consideran lenguas «en el margen de lo lingüístico» (Rodríguez y García, 1992: 2-3). En el extremo opuesto de la escala polar, los «lenguajes científicotécnicos» se caracterizan por un predominio de la precisión semántica. Son lenguajes que no tienen creatividad, etiquetajes.

De forma que los «lenguajes sectoriales» tienden a definirse de forma negativa, se consideran lenguajes que no pertenecen a un grupo social determinado, que no tienen delimitaciones conceptuales, con un predominio de los factores sociológicos y temáticos importante. Constituyen el eslabón intermedio —el tertium quid—entre los dos extremos opuestos de la escala. Son lenguajes que forman parte del sistema general de la lengua histórica pero tienen ciertas particularidades: son lenguajes de actividades y profesiones distintas.

Por ejemplo, voces y expresiones del lenguaje de la Educación son: adaptación curricular significativa, aprender haciendo, aprendizaje significativo, coevaluación, curriculum, curriculum abierto, didaxis, educación compensatoria, enseñanza individualizada, evaluación continua, evaluación criterial, heteroevaluación, mediador, objetivos mínimos, observación naturalista, paradigma mediacional centrado en el alumno, paradigma mediacional centrado en el profesor, proceso de enseñanza-aprendizaje, resiliencia, etc. Algunas de ellas son comprensibles por la comunidad de hablantes no especialistas pero otras requieren de un previo conocimiento de su significado.

Existen muchos «lenguajes sectoriales». El lenguaje deportivo tiene palabras conocidas por la comunidad de hablantes no especialistas pero otras específicas del ámbito: base, cadena, delantero, desmarque, escapada, larguero, tablero. Sucede lo mismo en el lenguaje del cine: acción alterna, profílmico, analepsias, catch, combo, contraplano, crominancia, DAT, dolby, drive-in, ecualizador). El lenguaje económicofinanciero también es un «lenguaje sectorial»: BAI, bache inflacionista, bund, déficit de la balanza de pagos, demanda agregada, desaceleración, descuento de dividendos, desmonetización, obligacionista, paridad.

$\mathrm{Al}$ igual que lo son el periodístico (banner, conferencia de prensa, corresponsalía, entradilla, fotocomposición, fotomecánica, infografía, lead, offset, segmentación de audiencias, sueltos), el político (bipartidismo, castrocomunismo, nepotismo, 
oligarquía, reelección, refundar, relegitimación) o el publicitario (anuncios flotantes, banner, branding, clic-down, CPA, CPL, CPM, gif animado, visitantes únicos).

Estos ejemplos del léxico de algunos «lenguajes sectoriales», debido al código que utilizan, están sometidos a la creatividad lingüística. Por esta razón, Rodríguez y García (1992: 3) aproximan el concepto de «lenguajes sectoriales» al de campo semántico o dominio de la experiencia, a la vez que le añaden el necesario componente sociológico — de nuevo, se retoma el «factor extralingüístico» para la caracterización de «lengua especial»-.

En sentido análogo, Rodríguez (1981: 114) define los «lenguajes sectoriales» como: «[...] aquellos ámbitos de una lengua histórica que, en virtud de las características extralingüísticas tanto de los objetos que se designan como del dominio social —«sujetos»— en que se los designa, quedan individualizados lingüísticamente, adoptando rasgos de los «argots» o de los «lenguajes científico-técnicos» (Ibid.).

Hay una amplia tradición entre los estudiosos de las «lenguas especiales» que tiende a diferenciar los «lenguajes sectoriales» de los «argots» y de los «lenguajes científico-técnicos». Según Whorf (1971), en la escala o continuum de las «lenguas especiales», la influencia de las variantes de «sujetos»-grupo social que crea su propia lengua- - «objetos» — realidades a las que se alude a través del lenguajeen el lenguaje, muestra el paso de un extremo a otro de la misma; el paso de una «lengua especial» a otra. Así pues, cada una de estas lenguas posee un léxico —un «objeto»— claramente distinto — aspecto que las encuadra en campos semánticos o dominios léxicos diferentes-, pero parece ser que los «lenguajes sectoriales» no tienen un grupo social singular —componente sociológico, factor extralingüístico.

Por tanto, las variantes de «objeto» $\mathrm{y}$ «sujeto», no sirven de elemento diferenciador para este tipo de lenguajes. Pero la neutralidad que presentan en esta oposición de variantes sí es exclusiva de los mismos, ya que en los otros tipos de «lenguas especiales» dichas variantes están bien delimitadas.

Según Rodríguez (1981) los «lenguajes sectoriales» son las «jergas de las profesiones y lenguajes afines, que identifican un determinado dominio social y de actividad» (Ibid.: 53). Para este autor, tres son las características que diferencian a estos lenguajes del resto de «lenguas especiales»: 1) no tienen una finalidad críptica; 2) no tienen dobletes en la lengua común; y, 3) en sentido análogo a Whorf (1971), son neutros en la oposición «sujetos»/»objetos».

Sin embargo, Rodríguez considera que en la categoría de las hablas sectoriales se deben incluir los «argots» vulgarizados —aquéllos que al ser transmitidos a través de los mass-media pierden su carácter secreto-, así como las lenguas tecnocientíficas «las que - pasan a tener un uso interdisciplinar o se integran en la lengua común—» (Rodríguez, 1981: 115).

Al ser un tertium quid, no constituye un lenguaje ni jergal, ni técnico; toma léxico y otras partículas gramaticales de las otras «lenguas especiales» — motivo que reafirma la definición negativa de los «lenguajes sectoriales»- Estas consideraciones de los «lenguajes sectoriales»— conducen a admitir que son lenguajes con número de hablantes ilimitado —-no se sabe a ciencia cierta cuántas hablas sectoriales existen, ni cuántos hablantes hacen uso de ellas-y con cierta tendencia a ser confundidos con los «argots» o asimilados con los «lenguajes científico-técnicos».

Hay autores que seleccionan una denominación diferente para referirse a los «lenguajes sectoriales». Por ejemplo, Sourdot (1991) utiliza la categoría de «jargots», 
dentro de la cual existen hablas específicas y creaciones personales, que no son ni crípticas ni científico-técnicas. Son tecnolectos utilizados con la finalidad de hacer inaccesible la comunicación a los no conocedores de dicho lenguaje y reforzar así ese sentimiento de identidad de los que sí pertenecen a un grupo social concreto.

Ejemplos de «jargots» son palabras que forman parte del habla de los malhechores, la jerga médica críptica —utilizada, en muchas ocasiones, para no poner nervioso al paciente (neo por neoplasia; necro por necropsia; acúfenos por estrés acústico)—, el lenguaje de los cazadores, el de los militares, o los que se han mencionado anteriormente.

Roffé (1996) también admite la categoría de «jargots» pero considera que sólo forman parte de la misma los «[ ] lenguajes especiales sin base directa greco-latina, hablados por comunidades restringidas que comparten las mismas actividades, y que no los emplean crípticamente de forma habitual, o sea, frecuentemente» (Roffé, 1996: 202).

Una denominación diferente se encuentra en Bellón (1995), quien considera el «lenguaje sectorial»: «[...] el léxico de las jergas sectoriales populares» (por ejemplo, el léxico deportivo, el taurino, el propio de la Semana Santa, el de los Carnavales de Cádiz, de la moda, de la música, de la política nacional e internacional, etc.). Por otra parte, González (2000) define los «lenguajes sectoriales» como aquéllos usos que de la lengua común hacen determinados sectores sociales. Equipara esta denominación a la de «subcódigos» y añade que «son las variedades lingüísticas dependientes de las situaciones del uso de la lengua y se caracterizan por tener un vocabulario especializado» (Ibid.: 116).

Este autor manifiesta que uno de los rasgos más característicos de las «lenguas sectoriales» es su vocabulario, ya que se produce una restricción en el sentido de las palabras; determinadas voces se utilizan con un significado particular y específico. Ejemplos de esta restricción en el significado de las palabras, sería necare en latín (procedente del sermo rusticus ${ }^{4}$ ), significa matar, pero el denominativo derivado de nex, necis indica «muerte provocada por veneno o hambre»; es decir, sin verter sangre. En el sermo rusticus tendría el sentido de «hacer morir por medio del agua» y, por analogía, en español anegar.

Tras diversos estudios en el campo del latín vulgar, González (2000) muestra como rasgo distintivo de estas «lenguas sectoriales» los diferentes significados que una misma palabra puede llegar a tener en función de su utilización en la lengua general o en la sectorial. Admite que el término manejado en el «lenguaje sectorial» es el que termina por imponerse en la lengua común. Asimismo, ofrece otra característica de las «lenguas sectoriales»: su influjo en el enriquecimiento de la lengua común a través de la utilización de préstamos extranjeros — por ejemplo carrus: carricare, cf. español cargar- (Ibid.: 121).

Por último, otro rasgo de este tipo de «lenguas especiales» lo constituye la utilización de formas diminutivas en lugar de simples. Ejemplos de esta renovación léxica, promovida por la sustitución del simple por su diminutivo, y tan frecuente en las lenguas técnicas y «sectoriales» serían: «acumula / acus, cf. español aguja;

4 GonzÁlez (2000) utiliza la expresión sermo rusticus para referirse a la variedad incorrecta y agramatical del latín. 
apicula / apis, cf. español abeja; ouicula /ouis, cf. español oveja; cepilla / cepa, cf. español cebolla» (Ibid.: 122).

La categoría de «lenguajes sectoriales» es un bloque indefinido, formado por todas aquellas variaciones lingüísticas que no son ni «argots», ni «lenguajes científico-técnicos».

En consecuencia, los «lenguajes sectoriales» son lenguajes definidos de forma negativa, con un componente sociológico resultante de la singularidad social de sus hablantes, sin función críptica, sin alteraciones fonéticas y con usos interdisciplinares que los aproximan a los «lenguajes científico-técnicos», a los «argots» o a la lengua general. En esta dirección se sitúan las obras de Bellón (1995), Gutiérrez (1991), Rodríguez (1981) y Rodríguez y García (1992). La tesis de Roffé (1996) difiere de las comúnmente adoptadas por el resto de autores en el sentido que considera «lenguajes sectoriales» o «jargots» aquéllos con base directa greco-latina, hablados por comunidades delimitadas temáticamente, sin creaciones personales y sin finalidad secreta.

En cambio, Sourdot (1991) sostiene que éstos deben tecnolectos o creaciones personales, que tengan la intención de enmascarar el significado. Esta posición sería más bien una aproximación a las jergas o al «argot».

A pesar de las posiciones definidas sobre la consideración de los «lenguajes sectoriales», Rodríguez (1981) añade una característica más: considera que carecen del principio semántico de "consustancialidad cuantitativa». Por esta razón, la relación que existe entre el significado de un término y su significante dependerá del uso que de ellos se haga. No se obtendrá, pues, una relación unívoca entre los dos componentes del signo lingüístico, salvo en el caso de los «lenguajes científicotécnicos». Lo que se observará en las hablas sectoriales serán dos sistemas lingüísticos: el propio o denotativo y el connotativo o desviación semántica.

En consecuencia, presentarán fenómenos de polisemia, homonimia, connotación, sinonimia, etc. De forma que será la carga connotativa de sus unidades, el elemento constitutivo, definitorio y diferenciador de su importancia en esta tipología lingüística "ya que su singularidad temático-social acentúa los valores expresivos de la connotación»(Rodríguez, 1981: 116).

En los «lenguajes sectoriales» los usos connotativos de los términos se concretan en creaciones léxicas que suponen fenómenos de sinonimia «porque aparece un nuevo significante del signo: el propio signo connotativo» y de homonimia o polisemia "porque aparece un nuevo significado para el significante del signo connotativo» (Ibid.). Así pues, los «lenguajes sectoriales» tienen un carácter difuso.

Por una parte, carecen del sentido críptico de los «argots», de la función de cohesión social de éstos y de la objetividad de los términos de los «lenguajes científico-técnicos». Por otra, no están construidos con términos semánticamente unívocos —aspecto que sí tienen los tecnicismos-.

Por tanto, los rasgos que lo diferencian de los otros tipos hacen que su definición sea negativa. El problema es que, autores como Rodríguez (1981), han destacado como propiedad principal las unidades connotativas; característica que también posee el léxico de la lengua general. Los aspectos más distintivos de los «lenguajes sectoriales» es que están desplazados por las características de la situación comunicativa en que se utilizan y por el tipo de interlocutores que participan en ella. De ahí que sea una categoría notablemente difusa. 


\section{Discusión DE LOS RESUltados y CONCLUSIONES}

El lenguaje de la Educación es un registro, una variedad funcional, dentro del sistema general de la lengua caracterizado por una temática específica, utilizado en situaciones comunicativas concretas, por determinados interlocutores y con intenciones diversas. En este sentido, el tema y las características pragmáticas del contexto en el que se produce la comunicación son elementos importantes a considerar. Muestra su producción científica con instrumentos lingüísticos universales que dominan los hablantes de un país: la lengua.

El conjunto al que pertenece el «lenguaje sectorial» de la Educación es el de la lengua de especialidad o «lenguas especiales» que constituyen, a su vez, un subsistema lingüístico que utiliza términos especializados y recursos lingüísticos para dotar de exactitud y erradicar la ambigüedad de la comunicación en un ámbito determinado (Lerat, 1997). Los aspectos más significativos que muestran la evolución de esta sociedad del conocimiento y que caracterizan y diferencian al «lenguaje sectorial» del resto de lenguajes, remiten a rasgos léxicos y sintácticos.

Dado que este lenguaje forma parte de un subsistema, pertenece tanto al sistema lingüístico general como a una «comunidad epistemológica» que comparte conocimientos afines. Establecer la frontera entre la lengua común y la de especialidad es, cuando menos, complicado, por la sencilla razón de que las lenguas de especialidad — dentro de las cuales se sitúa el lenguaje de la Educaciónemanan de la lengua común.

El único aspecto que cambia en una sublengua, en un lenguaje de especialidad, en el «lenguaje sectorial», son las denominaciones; es decir, los términos, las unidades léxicas (Benveniste, 1977: 94) y no el sistema lingüístico general.

De hecho, para que las unidades léxicas se puedan considerar términos, éstas deben formar parte de un campo de especialidad. Por esta razón, en el lenguaje de los docentes hay palabras que pertenecen a la lengua general y que sufren especializaciones (terminologización) y también existen términos que pertenecen al lenguaje común, tienen rasgos específicos en el «lenguaje sectorial» de la Educación y los pierden al ser usados por los hablantes (banalización).

En términos generales, la lengua de especialidad, formada por un conjunto de aspectos morfológicos, léxicos, sintácticos y textuales, pone a disposición de los especialistas una serie de recursos expresivos, comunicativos, discursivos para que una materia específica pueda desarrollarse de forma precisa en su contexto profesional.

Tal y como expone Sevilla (2003: 20): «se puede hablar de un lenguaje científicotécnico determinado por la forma en que la comunidad de científicos y técnicos emplea la lengua en el ejercicio de su profesión». Así, pues, el lenguaje de especialidad necesariamente implica asumir una temática, unos usuarios y unas situaciones de comunicación especializadas.

Pues bien, en ese contexto científico-técnico, en las ciencias exactas, experimentales, económicas, jurídicas, en ingeniería, en el deporte o en el comercio, el lenguaje escrito, fundamentalmente - concebido como sistema de comunicación y transmisión de información-y, en concreto, el léxico, difiere del utilizado por el resto de nativos. Esta distinción se debe a una especialización temática que establece que un lenguaje es especializado. Bien es cierto que, cada vez con más frecuencia, 
introducimos en nuestra vida cotidiana temas especializados. Este fenómeno recibe el nombre de banalización.

Sin embargo, el lenguaje utilizado en el campo de la Educación, en la escuela, en la Universidad, en Pedagogía, presenta términos especializados temáticamente acompañados de expresiones y de léxico perteneciente a la lengua común. Es comprensible, puesto que cuando se intercambia información con los padres/madres de un alumno, el lenguaje debe transmitir datos precisos de comportamiento, actitudes, rendimiento académico, niveles perceptivo-motrices, grado de atención, etc. de forma clara para que éstos (hablantes no especialistas) puedan comprenderlo sin olvidarnos de los aspectos claves de la Didáctica, la Organización Escolar, la Pedagogía y la Psicología que, de igual modo, se deben transmitir con transparencia.

Por tanto, es necesario dominar una serie de términos especializados y ser capaz de proporcionar explicaciones sencillas haciendo uso de la lengua común, como sistema de comunicación y como instrumento lingüístico de transmisión de información.

Este segundo criterio sobre la noción de especialidad es amplio, diverso y ambiguo, sujeto quizás a concepciones más subjetivas sobre dónde residen los límites de la especialización. En cambio, no deja de ser cierto que los términos que cualquier hablante puede introducir en una conversación informal remiten a una profesión especializada, tanto temática como pragmáticamente.

El ámbito científico-técnico forma parte de un lenguaje de especialidad porque presenta una temática específica, unas características inherentes a sus interlocutores, unos rasgos precisos de la situación comunicativa y una función comunicativa concreta, específica. En consecuencia, un texto especializado necesita una serie de reglas lingüísticas muy diferentes a las utilizadas por los hablantes en situaciones de comunicación cotidianas. Por tanto, estos aspectos son los que diferencian los textos de especialidad de los ordinarios y los que contribuyen a delimitar las fronteras entre la lengua común y la lengua de especialidad.

No es posible aludir exclusivamente al criterio temático, ya que, como señalan Sager, Dungworth y McDonald (1980) toda actividad humana requiere un mayor o menor grado de especialización. Por tanto, los aspectos pragmáticos —además de los gramaticales y léxicos- serán la pieza clave que contribuirá a clasificar el tipo de lenguaje utilizado.

Bien es cierto que posiciones como la de Picht y Draskau (1985) son operativas, ya que es posible pensar que cada lenguaje de especialidad se actualiza en distintos niveles de especialización —el máximo grado de especialización lo constituyen los textos de comunicación entre especialistas y, el menor, las comunicaciones de carácter divulgativo, dirigidas a la mayoría de la población-.

Lo que cabe plantearse es si la distinción de Picht y Draskau (1985) no forma parte inherente del concepto de lenguaje de especialidad. Esto es, aventurar la hipótesis de que los lenguajes de especialidad o alguno de sus tipos tienen tales características internas (gramaticales) y comunicativas (pragmáticas) que los delimitan como una clase intermedia entre la lengua general y los «lenguajes científico-técnicos»; lo que se ha denominado "nivel umbral».

El lenguaje de la Educación presenta palabras de la lengua general con significado original, palabras del lenguaje general que adquieren en contextos 
especializados un sentido diferente (coevaluación, ejemplificación, paradigma,), y algunos términos técnicos que lo aproximan a los «lenguajes científico-técnicos» (discalculia, resiliencia). Que este lenguaje tenga este tipo de léxico se debe a que pertenece a un ámbito profesional especializado (el campo de la Pedagogía, la Organización Escolar, la Psicología, etc.) que utiliza términos ligados a un subconjunto profesional con el sistema lingüístico de la lengua general.

Los términos de este lenguaje se caracterizan por tener rasgos léxicos comunes con las palabras de la lengua general, a los que se añade una terminología idiosincrásica del ámbito profesional de la comunidad epistemológica de la Pedagogía. En cierto modo, es natural que se encuentren términos especializados y palabras y expresiones sintácticas de la lengua común, porque el conocimiento científico se crea a partir del genérico y, en consecuencia, el «lenguaje sectorial» de la Educación encuentra su aposento lingüístico en la lengua general. Por ello, utiliza palabras de su vocabulario general que progresivamente se especializarán, concretándose en expresiones con diversos grados de lexicalización: adaptación curricular no significativa, aprendizaje cooperativo, centros de interés, educación intercultural, plan de acción tutorial.

Deigual modo, recurre a las siglas como sustitutos de términos técnicos, facilitando compuestos sintagmáticos que evitarán, entre otros, el problema de la polisemia tan característico de los «lenguajes científico-técnicos»: ACNEAE («Alumno Con Necesidad Específica de Apoyo Educativo»), AC («Actividades Complementarias»), ACI («Adaptación Curricular Individualizada»), MLP («Memoria a Largo Plazo»), PCPI («Programas de Cualificación Profesional Inicial»), PEC («Proyecto Educativo de Centro»), PDI («Pizarra Digital Interactiva»), etc.

Las siglas son un procedimiento muy habitual en este «lenguaje sectorial». Suplen la carencia de términos técnicos (vocabulario específico) - propios de los «lenguajes científico-técnicos»- y le otorgan al discurso pedagógico cientificidad y universalidad. Su tipología (siglas propias e impropias) tiene una característica especial; en muchas ocasiones, los significantes son los mismos pero el significado es diferente. Por ejemplo, la sigla $C I$ puede remitir al «Cociente Intelectual» o a un «Centro de Interés». Son sustantivos y actúan como tales.

El uso de este recurso lingüístico permite a los profesionales de la Educación comunicarse y aludir a conceptos, teorías y aspectos curriculares diversos. Son una fuente de recursos amplia, existente también en otras disciplinas científicas, pero importante en este «lenguaje sectorial» por su cantidad y función. Se han consolidado en este lenguaje de especialidad, insertándose completamente en los discursos de sus hablantes especialistas en igualdad de condiciones que cualquier otro sustantivo o expresión, sin precisar de una decodificación para su comprensión. Muestran un grado de lexicalización importante porque, entre otras razones, muchas de ellas se han aceptado en la lengua general y se han consolidado en los discursos de especialidad de forma que constituyen secuencias de lexemas estereotipadas.

Por otra parte, ellenguaje de la Educación tiene términos que, aunqueinicialmente formen parte del vocabulario de la lengua general, han sufrido modificaciones en su extensión semántica. Algunos amplían sus rasgos (especialización semántica: área, autoaprendizaje). Otros reducirán su extensión semántica (restricciones semánticas: ambiente, anécdota, contenido, triangulación). Y, finalmente, otras 
unidades léxicas han sufrido una transferencia de significado (cambio semántico: acomodación, desvanecimiento). Estos recursos presentes en la formación y usos de las unidades que conforman el lenguaje de Educación muestran encrucijadas culturales y lingüísticas (anglicismos: biofeedback, borderline, hipermedia, overlearning, performance).

Los términos que conforman este lenguaje tienen un uso especializado y restringido pero, debido a la interacción que se produce entre la vida cotidiana y los descubrimientos de la ciencia, es decir, entre la lengua general y la lengua de especialidad, el vocabulario que presenta está formado por términos situados en un punto intermedio entre la lengua general y los «lenguajes científico-técnicos», en un «nivel umbral». Este aspecto hace que el léxico del «lenguaje sectorial» de la Educación se considere "subtécnico» o "semitécnico».

El léxico de este lenguaje de especialidad no sólo hace uso de léxico general y especializado, sino también estructuras sintácticas de la lengua común, en muchas ocasiones formadas por elementos léxicos especializados. Los interlocutores en una situación comunicativa en cualquier ámbito de la Educación son profesores, padres, madres, alumnos, orientadores, investigadores, etc. En un porcentaje considerable, los padres y madres de los alumnos no han cursado estudios básicos.

En consecuencia, es necesario utilizar un lenguaje que sea compresible para ellos. Estas situaciones de intercambio comunicativo entre hablantes profesionales y no profesionales son constantes en el periodo de escolaridad obligatoria (Educación Infantil, Primaria y Secundaria) porque la transmisión de valores educativos y sociales no sólo debe proporcionarse desde los centros, también a través de una constante actuación con los padres, de modo que participen en el proceso educativo. Expresiones del tipo dislexia diseidética, incoordinación vasomotora, inmadurez articulatoria, sindrome de asperger, aparecen con frecuencia en el lenguaje de los docentes y deben ser transmitidas con eficacia a los padres para que sean conscientes de los problemas de su hijo y colaboren en la resolución de problemas.

El léxico creado por la comunidad epistemológica de la Pedagogía utiliza, en contextos comunicativos especializados, formas de contenido que tienen significantes distintos de signo. Ello parece suponer que sea un léxico exclusivo de la Educación y diferente al de la lengua general y al de otras disciplinas científicas pero es una vinculación secundaria del rasgo «técnico» (Rodríguez, 1981), donde se produce un engendramiento de un léxico nuevo y una consecuencia de los préstamos intralingüísticos, además de los criterios pragmáticos y comunicativos de la esfera profesional que conforman lingüísticamente el dominio de la experiencia de la Pedagogía.

Esto no implica que no sea necesario un análisis semántico de los términos del «lenguaje sectorial» de la Educación. El léxico que constituye esta disciplina es ontológico; antes de que un término creado se utilice en una comunidad científica, se le atribuye a esa unidad léxica una asignación de un nombre a un concepto, a una noción. Evidentemente, esto no justifica un análisis conceptual en cuanto a campos semánticos, pero sí evidencia que este lenguaje, como sucede con el resto de lenguajes de especialidad o «lenguajes científico-técnicos», presenta dominios no sólo léxicos sino también conceptuales. Esos dominios contienen valores 
lingüísticos especializados y conforman esferas semánticas que sólo comparten los miembros de una disciplina científica.

Las diferentes lenguas, ya estén vivas o muertas, ofrecen su sistema lingüístico para asegurar la transmisión de conocimiento. La multidisciplinariedad también se aplica, pues, al campo lingüístico. Las lenguas que han permitido el desarrollo y crecimiento del "lenguaje científico-técnico», del que en cierto modo forma parte el «lenguaje sectorial» de la Educación, han sido el inglés, el griego clásico y el neogriego.

Dicha multidisciplinariedad se materializa al observar el uso que los profesionales de la Educación hacen de determinados términos. Presentan un orden jerárquico y clasificatorio. Muestran economía lingüística en el discurso pragmático y contienen calidad en la presentación de la información. No son indicativos de emociones y, en algunas ocasiones, recurren a la utilización de fórmulas pedagógicas y estadísticas que acompañan la información presentada.

El empleo del léxico general, léxico específico, siglas y determinadas expresiones lexicalizadas —en buena parte- caracterizan al lenguaje de la Educación. No es un lenguaje técnico - los términos no presentan univocidad semántica y las situaciones comunicativas tienen lugar entre especialistas y no especialistas, por lo que el lenguaje es común-, pero hace uso de determinadas unidades terminológicas que lo diferencian del lengua general. Por ello, forma un «nivel umbral», intermedio entre el «lenguaje científico-técnico»—con sus terminologías - y la lengua común.

Para algunos autores (Alcaraz, 2007) el detonante del empleo de términos técnicos es la llamada sociedad del conocimiento, creada en la primera década del siglo XXI. Constituye el marco de desarrollo de las «lenguas profesionales y académicas» o lenguas de especialidad. Las razones que conducen a los especialistas a analizar estas lenguas pueden ser diversas: «replanteamiento de la división tradicional del conocimiento; interdisciplinariedad epistemológica; deseo de conocer las estrategias cognitivo-comunicativas que emplean sus actores en las diversas situaciones»(Alcaraz, 2007: 3-4).

En primer lugar, dentro de la denominada sociedad del conocimiento se encuentra información que, en muchas ocasiones, se acumula pero no crea conocimiento. Si se considera que el principal objetivo de la ciencia es construir conocimiento, se debe seleccionar y utilizar adecuadamente la ingente cantidad de información para así filtrarla y construir, en las diferentes disciplinas, conocimiento científico. Esta sociedad del conocimiento ha creado las comunidades epistemológicas (knowledge communities) a través de las cuales las áreas de conocimiento encuentran su difusión, muestran su historia, forman congresos e intercambios profesionales y publican sus experimentaciones científicas logrando su extensión a nivel mundial.

Estas comunidades epistemológicas son las receptoras de los conocimientos de una especialidad y también son las responsables de dos cuestiones básicas: consolidar su forma de expresión —registro, recursos lingüísticos, procedimientos terminológicos, características pragmático-discursivas, orden oracional- y creación de nuevas unidades léxicas —neologismos, anglicismos, tecnicismos, etc.- -

La proliferación de términos que acontece debido a la información que tenemos a nuestro alcance, ha propiciado la creación de las llamadas 
«comunidades virtuales», que ponen a nuestra disposición un sinfín de términos considerados palabras clave. La ciencia y la tecnología, en general, son los ámbitos científicos que mayor difusión y desarrollo encuentran en la denominada sociedad del conocimiento. La razón es lógica: son disciplinas que evolucionan a una velocidad de vértigo y que requieren de términos nuevos para designar nuevas realidades.

En segundo lugar, en la sociedad del conocimiento cobra especial importancia la interdisciplinariedad. En las comunidades epistemológicas, creadas en función del ámbito profesional de desarrollo, intervienen determinados saberes que pertenecen indistintamente a campos profesionales diferentes. Todo ello propicia una reflexión teórica y una aplicación práctica de las «lenguas académicas y profesionales», de las lenguas de las comunidades epistemológicas de los médicos, docentes, juristas, científicos, poetas, etc. (Alcaraz, 2007: 7).

Si bien estas lenguas se han convertido en códigos lingüísticos y comunicativos complejos, muestran a través de su léxico un vocabulario singular e idiosincrásico de una comunidad epistemológica, de un ámbito profesional. No obstante, existen otros componentes que contribuyen en la caracterización de las lenguas de especialidad o "lenguas profesionales y académicas» como son su morfosintaxis, su estructuración discursiva, sus elementos pragmáticos, sus géneros profesionales recogidos en textos escritos que alcanzan gran difusión en el público receptor y su anisomorfismo cultural.

En tercer lugar, resulta inevitable que para los estudiosos del lenguaje, la caracterización y tipologización de las «lenguas profesionales y académicas»o «lenguas especiales» sea un menester atractivo y se le dedique un estudio lingüístico en profundidad.

Diversos son los ámbitos que complementan el «nivel umbral» al que pertenece el «lenguaje sectorial» de la Educación. Por ello, únicamente a través de una complementación paradigmática es viable el estudio de este «lenguaje sectorial», que va mucho más allá que el estudio de un determinado lenguaje. Las «lenguas especiales» conllevan un agrado de civilización, de especialización que, entre todos, hemos alcanzado en la sociedad del conocimiento de este siglo XXI.

El léxico especializado confiere a este lenguaje de la Educación un marco epistemológico cuya función principal reside en delimitar una esfera de objetos y de relaciones que los diferentes miembros de la comunidad educativa comparten. Esta esfera está formada por términos que designan conceptos concretos de la disciplina de la Educación. Son los criterios pragmáticos y comunicativos que utilizan los especialistas en sus comunicaciones —orales y escritas- los que hacen que estos términos especializados del campo de la Pedagogía se diferencien del léxico de la lengua general, dado que los profesionales utilizan formas de contenido distintas expresadas por significantes distintos de signo.

El «lenguaje sectorial» de la Educación, pues, está fuertemente vinculado a su dominio de la experiencia. La Educación está estrechamente relacionada con el nivel sociológico y ello supone una constante interacción con padres, con educadores sociales, con colaboradores de actividades extraescolares, con museos, con centros lúdicos, etc. Sólo es posible comunicarse en estas situaciones con un «lenguaje sectorial». 


\section{REFERENCIAS BIBLIOGRÁFICAS}

Alcaraz, E. (2006). «Aproximación al lenguaje de la Farmacia», An. R. Acad. Nac. Farm., n. 72, pp. 344-360.

Alcaraz, E. (2007). El inglés jurídico norteamericano. Barcelona: Ariel.

Becerra, J. Ma (1992). Lenguas especiales de Andalucía. Repertorios léxicos. Granada: Servicio de Publicaciones Universidad de Granada.

Bellón, J. A. (1995). «Creaciones léxicas en el lenguaje popular», Actas de las II Jornadas sobre el estudio y la enseñanza del léxico, pp. 33-48. Granada: Universidad de Granada.

Beccaria, G. L. (1973). I linguaggi settoriali in Italia. Universidad de Milán: Milán.

Benveniste, E. (1977). Problemas de lingüística general II. Madrid: Siglo XXI.

Berruto, G. y Berreta, M. (1977). Lezioni di sociolingüística e lingüística applicata. Italia: Nápoles.

Calvi, $\mathrm{M}^{\mathrm{a}}$ V. (2005). El español del turismo: problemas didácticos, sitio Web de la Università Degli Studi di Bergamo: http://ideas-heilbronn.org/artic.htm [03/02/2014].

Casares, J. (1969). Introducción a la lexicografía moderna. Madrid: CSIC.

Charlton, B. MD y Andras, P. (2005). «Modernizing UK health services: 'short-sharp-shock' reform, the NHS subsistence economy, and the spectre of health care famine», Journal of Evaluation in Clinical Practice, n. 11:2, pp. 111-119.

Duarte, C. (1986). Llengua y Administració. Barcelona: Eds. de la Magrana.

Engel, M. U. (1970). «Langues de Specialité et Langue Scientifique : Recherches en République Fédérale Allemande», Actes du Stage de Saint-Cloud, n. 23-30, pp. 31-49.

González, T. (2000). «La contribución de los lenguajes sectoriales a la evolución y renovación del latín», en García, B. (Ed.): Latín vulgar y tardío: homenaje a Veikko Väänänen. Madrid: Ediciones clásicas, pp. 111-121.

Gutiérrez, B. (1998). La ciencia empieza en la palabra. Análisis e historia del lenguaje científico. Barcelona: Península.

Hernán, L. (1979). «Lenguas especiales». Documentos lingüísticos, pp. 68-74.

Hoffmann, L. (1979). "Seven Roads to LSP», Fachsprache, n. 1-2, pp. 28-38.

Kocourek, R. (1982). La langue française de la technique et de la science. Wiestbaden: Brandstetter.

Lerat, P. (1997). Las lenguas especializadas. Barcelona: Ariel.

Martín, Ma A. (1997). «Formación de palabras y lenguaje técnico», Revista Española de Lingüística, n. 27, 2, pp. 317-339.

Martín, J., Ruiz, R., Santaella, J., y Escánez, J. (1996). Los lenguajes especiales. [Lenguaje jurídico-administrativo - Lenguaje científico-técnico - Lenguaje humanístico - Lenguaje periodístico y publicitario - Lenguaje literario]. Granada: Comares.

Martínez, J. A. (2006). «Lenguas de especialidad y léxico: algunas dificultades en la traducción de términos», Romansk Forum, n. 21 (2), pp. 41-50.

Picht, H., y Draskau, J. (1985). Terminology: an introduction. Guilford: University of Surrey.

Rodríguez, B. (1981). Las lenguas especiales. El léxico del ciclismo. León: Colegio Universitario de León.

Rodríguez, B., y García, P. (1992). "Lenguajes científico-técnicos y diccionario», III Simposio de RITerm http://www.riterm.net/actes/3simposio/rodrig.htm [16/11/2014].

Roffé, A. (1996). «Desarrollo de la conceptualización y designación jergal hispano-francesa. Enmiendas propuestas», Revista de Filología Francesa, n. 9, pp. 196-204.

Rondeau, G. (1983). Introduction à la terminologie. Chicoutimi Québec: Gaëtan Morin.

Sager, J. C., Dungworth, D., y Mcdonald, P. F. (1980). English Special Languages: Principles and Practice in Science and Technology. Brandstetter, Wiesbaden.

Santamaría, I. (2005). El léxico de la ciencia y de la técnica. Barcelona: Graó. 
Schmitt, Ch. (1992). «Spanish: Fachsprachen Tecnolectos», en Holtus, G., Metzeltin, M. y Schmitt, C. (Eds.), Lexikon der Romanistischen Linguistik. Tubinga: Niemeyer, pp. 295327.

Sevilla, M. (2003). «Una clasificación del texto científico-técnico desde un enfoque multidireccional», Language Design, Journal of Theoretical and Experimental Linguistics, n. 5, pp. 93-98.

Sourdot, M. (1991). «Argot, jargon, jargot », Langue française, n. 90, pp. 13-27.

Taylor, S. J., y Bogdan, R (1992). Introducción a los métodos cualitativos de investigación. Barcelona: Paidós.

Trujillo, R. (1974). «El lenguaje de la técnica», Doce ensayos sobre el lenguaje, pp. 195-211. Vendryes, J. (1929). Le langage. Introduction linguistique à l'histoire. París : La Renaissance. Whorf, B. L. (1971). Lenguaje, pensamiento y realidad. Barcelona: Barral.

Wulff, E. (1981). Lenguaje y lenguas. Barcelona: Salvat.

Universidad de Zaragoza

Rebeca Soler Costa

rsoler@unizar.es

[Artículo aprobado para publicación en diciembre de 2016] 